Article

\title{
Structural Features of Alkaline Extracted Polysaccharide from the Seeds of Plantago asiatica L. and Its Rheological Properties
}

\author{
Jun-Yi Yin ${ }^{1,+}$, Hai-Hong Chen ${ }^{1,+}{ }^{,}$Hui-Xia Lin ${ }^{2}$, Ming-Yong Xie ${ }^{1}$ and Shao-Ping Nie ${ }^{1, *}$ \\ 1 State Key Laboratory of Food Science and Technology, Nanchang University, Nanchang 330047, China; \\ junyi86@163.com (J.-Y.Y.); chh0810ncu@163.com (H.-H.C.); myxie@ncu.edu.cn (M.-Y.X.) \\ 2 Xiamen Huaxia College, Xiamen 361024, China; lin1986410@163.com \\ * Correspondence: spnie@ncu.edu.cn; Tel./Fax: +86-791-8830-4452 \\ + These authors contributed equally to this work.
}

Academic Editor: Derek J. McPhee

Received: 22 June 2016; Accepted: 1 September 2016; Published: 6 September 2016

\begin{abstract}
Polysaccharide from the seeds of Plantago asiatica L. has many bioactivities, but few papers report on the structural and rheological characteristics of the alkaline extract. The alkaline extracted polysaccharide was prepared from seeds of P. asiatica L. and named herein as alkaline extracted polysaccharide from seeds of P. asiatica L. (PLAP). Its structural and rheological properties were characterized by monosaccharide composition, methylation, GC-MS and rheometry. PLAP, as an acidic arabinoxylan, was mainly composed of 1,2,4-linked Xylp and 1,3,4-linked Xylp residues. PLAP solution showed pseudoplastic behavior, and weak gelling properties at high concentration. Sodium and especially calcium ions played a significant role in increasing the apparent viscosity and gel strength.
\end{abstract}

Keywords: seeds of Plantago asiatica L.; alkaline extracted polysaccharide; structure; rheology

\section{Introduction}

Arabinoxylan is widely distributed around the world. It is non-starch polysaccharide, and composed of a linear $\beta-1,4$-linked Xylp backbone. Ara residues are usually distributed in the side chain. Residues of $\beta-1,4$-linked Xyl $p$ in the backbone are substituted at some $O-2$ and/or O-3 by Ara and other residues. Arabinoxylan is usually considered to play in beneficial roles in stimulating prebiotic growth [1,2], reducing cardiovascular risk [3], and exhibiting immunoregulation [4] and anti-tumor [5] activities. Psyllium, a mucilaginous polysaccharide material from seed husks, is also an excellent source of arabinoxylan [6-10].

There are more than 200 species of Plantago, which are used extensively all over the world. Polysaccharide extracted from Plantago seeds is one of bioactive components which were widely reported in recent years [11]. Previous studies mainly focused on the polysaccharide extracted from Plantago genus, to characterize its rheological behavior and gelling properties [12-14]. However, as yet few reports has paid enough attention to the polysaccharide extracted from P. asiatica L., except for a very limited number of reports in which the water-soluble polysaccharide has been confirmed as a typical arabinoxylan [15,16] that exhibited weak gelling property [17] and promoted colon health [18-20].

Therefore, the aim of this paper was to investigate the structural and rheological properties of alkaline extracted polysaccharide. The alkaline extracted polysaccharide (named hereafter as PLAP) was prepared from the seeds of P. asiatica L. Techniques including monosaccharide compositional analysis, methylation analysis, together with gas chromatography-mass spectrometry 
(GC-MS), were combined to characterize the molecular structural features of the PALP. Additionally, the rheological properties of PALP with an addition of different ratio of sodium or calcium ions were also characterized by rheometry. Relationships between the structural features and rheological performance of the P. asiatica L. polysaccharide are discussed.

\section{Results}

\subsection{Structural Characterization}

Table 1 shows the basic molecular structural features, in which PALP was characterized to be acidic polysaccharide that contained $20.5 \%$ of uronic acid. Xyl and Ara, whose molar ratio was 4.1 , were considered as the main compositional monosaccharides since they accounted for a significantly higher proportion of the contents. In contrast, Rha, Glc and Ga detected at low levels were the minor compositional monosaccharides for the PALP. These results indicated that PALP should be considered an arabinoxylan. In addition, the intrinsic viscosity of PALP diffused in $0.1 \mathrm{M} \mathrm{NaCl}$ solution was measured at $5.81 \mathrm{dL} / \mathrm{g}$. The molecular weight of PLAP would be much higher than $3.80 \times 10^{-6}$ as the sample recovery was only $13.9 \%$ when it was subjected for HPSEC analysis. The low sample recovery could be explained by the phenomenon that the polysaccharide hardly passed through the filter membrane. Most of the sample was retained by the filter.

Table 1. Physicochemical properties of PLAP.

\begin{tabular}{|c|c|c|c|c|c|c|c|c|c|}
\hline \multirow{2}{*}{$\begin{array}{l}\text { Sugar } \\
(\%)\end{array}$} & \multirow{2}{*}{$\begin{array}{l}\text { Protein } \\
(\%)\end{array}$} & \multirow{2}{*}{$\begin{array}{l}\text { Uronic Acid } \\
(\%)\end{array}$} & \multirow{2}{*}{$\begin{array}{c}(\eta) \\
(d L / g)^{a}\end{array}$} & \multirow{2}{*}{$\begin{array}{l}\text { Molecular Weight, } \\
M_{\mathrm{w}}\left(\times 10^{-6}\right)^{\mathrm{b}}\end{array}$} & \multicolumn{5}{|c|}{ Monosaccharide Composition (Molar Ratio) } \\
\hline & & & & & Rha & Ara & Xyl & Glc & Gal \\
\hline 82.84 & 0.68 & 20.50 & 5.81 & 3.80 & 1.00 & 15.41 & 63.95 & 1.29 & 2.58 \\
\hline
\end{tabular}

The glycosyl-linkage composition results of PLAP are presented in Table 2. The main residues in PLAP were T-linked Araf (5.06\%), 1,3-linked Araf (10.22\%), T-linked Xylp (10.88\%), 1,3-linked Xylp (11.39\%), 1,4-linked Xylp (6.19\%), 1,2,4-linked Xylp (13.30\%) and 1,3,4-linked Xyl $p$ (38.98\%). 1,2,4-linked Xylp and 1,3,4-linked Xyl $p$ were the primary branched sugar residues, indicating side chains probably connected to the backbone through $\mathrm{O}-2$ and $\mathrm{O}-3$ positions of 1,4-linked Xyl $p$ residues. PLAP might be highly branched, since it was found to be rich in 1,2,4-linked Xyl $p$ and 1,3,4-linked Xylp residues. Other residues, such as T-linked Galp, 1,4-linked Galp, 1,2-linked Rhap and 1,3-linked Glcp, were also detected in small amounts. According to previous reports [12-14], this kind of polysaccharide from Plantago seeds should be considered as an arabinoxylan whose backbone was probably composed of 1,4-linked Xyl $p$, including 1,2,4-linked Xyl $p$ and 1,3,4-linked Xyl $p$.

Table 2. Glycosyl-linkage compositions of PLAP.

\begin{tabular}{ccc}
\hline Residue Linkage & Molar Ratio $^{\text {a }}$ & $m / z$ \\
\hline T-linked Araf & 5.06 & $43,71,87,101,102,118,129,161$ \\
1,3-linked Ara $f$ & 10.22 & $43,69,87,99,113,118,129,233$ \\
T-linked Xylp & 10.88 & $43,59,87,88,101,102,117,118,161,162$ \\
1,3-linked Xyl $p$ & 11.39 & $43,59,87,101,117,118,129,173,174$ \\
1,4-linked Xylp & 6.19 & $43,87,99,102,118,129,162,189$ \\
1,2,4-linked Xyl $p$ & 13.30 & $43,57,71,87,88,129,130,189,190$ \\
1,3,4-linked Xylp & 38.98 & $43,85,87,99,118,201,261$ \\
T-linked Galp & 1.12 & $43,59,71,87,101,102,118,129,145,161,162,205$ \\
1,4-linked Gal $p$ & 1.19 & $43,87,99,102,113,118,129,162,173,233$ \\
1,2-linked Rha $p$ & 0.65 & $43,88,89,100,101,115,130,131,161,190$ \\
1,3-linked Glc $p$ & 0.40 & $43,71,87,101,118,129,161,234$ \\
\hline a Calculated a percentage of partially-methylated alditol acetates present, based on the peak area.
\end{tabular}




\subsection{Rheological Properties of PLAP}

\subsubsection{Steady State Shear Properties}

The flow curves for a series of concentrations of PLAP ranging from $0.1 \%$ to $3.0 \%$ in aqueous solution at $25^{\circ} \mathrm{C}$ are shown in Figure 1. The typical curves of PLAP solutions showed shear thinning behavior, as the viscosity decreased with increasing shear rate. It was more obvious when the concentration was higher than $1.0 \%$. For lower concentrations, the viscosity depended less on shear rate. Similar effects of concentration on viscosity of arabinoxylan from Plantago family [12,13] and other resources [21,22] has also been observed.

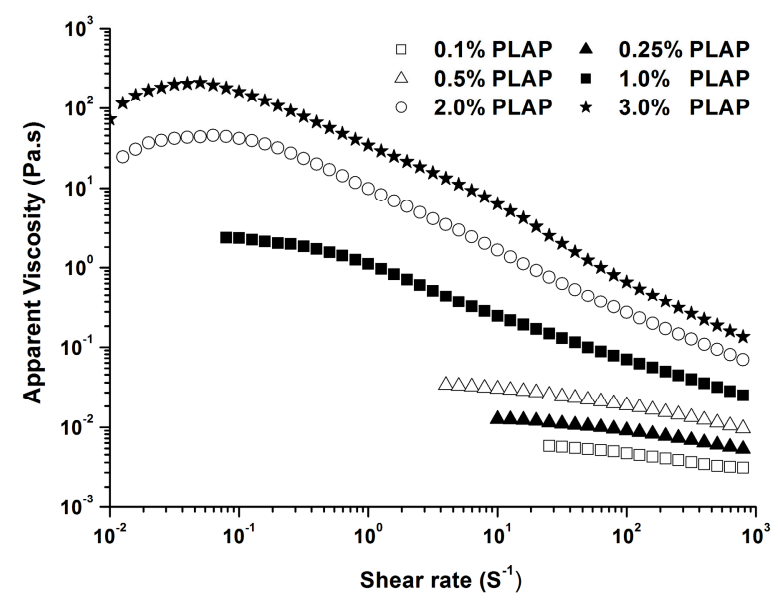

Figure 1. Effect of polysaccharide concentration on apparent viscosity of PLAP at $25^{\circ} \mathrm{C}$.

The polysaccharide solutions showed pseudoplastic behaviour as the temperature increased, but its apparent viscosity decreased dramatically with the increasing temperature (Figure 2). Several interactions occur for polysaccharides in solution, such as hydrogen and electrostatic bonds, and entanglements. When the disruption rate of these interactions reaches a similar level as their generation rate, a constant apparent viscosity is observed, named the Newtonian plateau. A Newtonian region in the low shear rates was observed, especially at the temperature of $60.0^{\circ} \mathrm{C}$. Both the Cross and Carreau flow models could be used to describe the shear-thinning behavior of polymer solutions, and calculate zero shear rate viscosity $\left(\eta_{0}\right)$. Herein, the Cross flow model was used to evaluate the flow behavior of PLAP solutions at different concentrations.

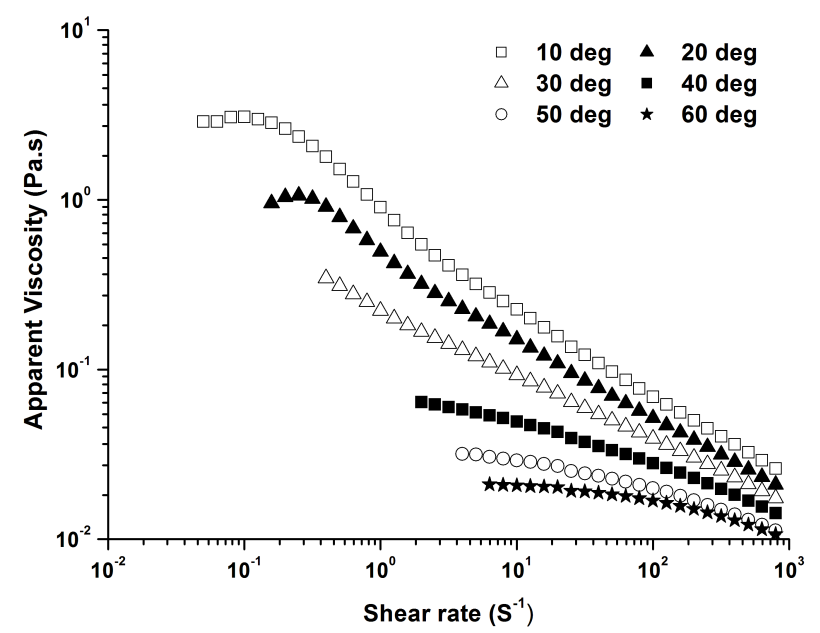

Figure 2. Effect of temperature on apparent viscosity of $1.0 \%$ PLAP. 
The Cross equation is as follows:

$$
\eta=\eta_{\infty}+\left(\eta_{0}-\eta_{\infty}\right) /(1+\alpha \gamma)^{m}
$$

where $\eta$ is the apparent viscosity, $\eta_{0}$ is the zero shear rate viscosity which is obtained by measuring the viscosity at a range of low shear rate and extrapolating to zero shear rate, $\eta_{\infty}$ is the limiting viscosity infinite shear rate, $\alpha$ is a time constant related to the relaxation time of polysaccharide in solution, $m$ is a dimensionless exponent. The Cross equation generally describes well the shear rate dependence of aqueous polysaccharide solutions. It was chosen to calculate $\eta_{0}$ and relaxation time. The values of the parameters obtained by fitting above equation to the tested data are shown in Tables 3 and 4, respectively. An increase of $\eta_{0}$ and $\alpha$ values with the increase of polysaccharide concentration was found, while both of them decreased as the temperature went up. The relaxation time ( $\alpha$ value) decreased with increasing temperature, suggesting that formation of new interactions between molecules predominated over the rate of their disruption.

Table 3. Parameters of the Cross model for the range of concentrations studied.

\begin{tabular}{cccc}
\hline Concentration (wt \%) & $\boldsymbol{\eta}_{\mathbf{0}}{ }^{\mathbf{a}}$ (Pa.s) & $\boldsymbol{\alpha}^{\mathbf{b}} \mathbf{( s )}$ & $\mathbf{m}^{\mathbf{c}}$ \\
\hline 0.10 & 0.0104 & 0.0174 & 0.3402 \\
0.25 & 0.0160 & 0.0056 & 0.4732 \\
0.50 & 0.0448 & 0.0204 & 0.4615 \\
1.0 & 1.8271 & 1.3301 & 0.5003 \\
2.0 & 44.0297 & 4.4526 & 0.8284 \\
3.0 & 300.2550 & 9.4121 & 0.8788 \\
\hline
\end{tabular}

${ }^{\mathrm{a}} \eta_{0}$ : Zero shear rate viscosity; ${ }^{\mathrm{b}} \alpha$ : a time constant of the power law; ${ }^{\mathrm{c}} \mathrm{m}$ : Dimensionless constant.

Table 4. Parameters of the Cross model for the range of temperatures studied.

\begin{tabular}{cccc}
\hline Temperature & $\boldsymbol{\eta}_{\mathbf{0}}{ }^{\mathbf{a}}$ (Pa.s) & $\boldsymbol{\alpha}^{\mathbf{b}} \mathbf{( s )}$ & $\mathbf{m}^{\mathbf{c}}$ \\
\hline 10 & 7.8691 & 34.1772 & 0.4173 \\
20 & 2.4583 & 15.1757 & 0.4755 \\
30 & 0.5766 & 3.3620 & 0.5506 \\
40 & 0.0966 & 0.0917 & 0.5945 \\
50 & 0.0392 & 0.0094 & 0.5508 \\
60 & 0.0226 & 0.0015 & 0.4250 \\
\hline
\end{tabular}

a $\eta_{0}$ : Zero shear rate viscosity; ${ }^{\mathrm{b}} \alpha$ : a time constant; ${ }^{\mathrm{c}} \mathrm{m}$ : Dimensionless constant.

The Arrhenius equation is usually taken to describe the temperature dependence of the apparent viscosity for an ideal Newtonian liquid, as shown in the following equation:

$$
\log \eta=\log \mathrm{A}+\mathrm{E}_{\mathrm{a}} / \mathrm{RT}
$$

where $\eta$ is the apparent viscosity, $A$ is a constant, $E_{a}$ is the activation energy for viscous flow, and $R$ is the gas constant. According to this equation, $\mathrm{E}_{\mathrm{a}}$ could be calculated at zero-shear rate viscosity which was estimated by the Cross equation $\left(\log \eta=5220 / T-17.53, R^{2}=0.989\right)$. The value of $E_{a}$ was calculated to be $43.40 \mathrm{~kJ} / \mathrm{mol}$.

\subsubsection{Viscoelastic Properties}

The mechanical spectra (frequency dependence of storage modulus $\left(G^{\prime}\right)$, and loss modulus $\left(G^{\prime \prime}\right)$ ) of PLAP at $25{ }^{\circ} \mathrm{C}$ are shown in Figure 3. For the frequency sweep tests, the strain used in all the experiments was within the linear viscoelastic region where the gel structure was not damaged. PLAP showed typical weak-gel structure: the values of $G^{\prime}$ were higher than those of $G^{\prime \prime}$ during the whole experimental range [23], except for $1.0 \%$ PLAP. Both $G^{\prime}$ and $G^{\prime \prime}$ showed a dependency on frequency and concentration. The higher the concentration, the less dependency the $G^{\prime}$ on frequency 
(Figure 3). The increase in $\mathrm{G}^{\prime \prime}$ as a function of polysaccharide's concentration suggested a higher viscosity contribution to the gel structure. More solid-like behavior was observed for those solutions at high concentrations. This may be due to an increased number of junction zones between the polymer chains at higher concentration [24,25]. A higher number of intramolecular junctions at lower concentration do not contribute to intermolecular cross-linking.

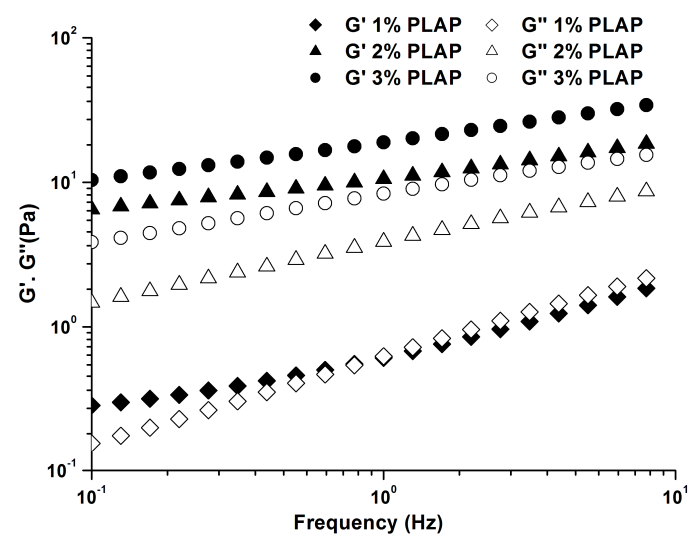

Figure 3. Effect of polysaccharide concentration on storage $\left(\mathrm{G}^{\prime}\right)$ and loss $\left(\mathrm{G}^{\prime \prime}\right)$ moduli of PLAP at $25^{\circ} \mathrm{C}$.

Figure 4a presents the change of $\mathrm{G}^{\prime}$ and $\mathrm{G}^{\prime \prime}$ of $3.0 \%$ PLAP as the temperature ranged from 5 to $78^{\circ} \mathrm{C}$. The heating and cooling curve $\left(\mathrm{G}^{\prime}\right)$ of PLAP was not superimposed. As the temperatures increased during the range lower than $30^{\circ} \mathrm{C}$, both $\mathrm{G}^{\prime}$ and $\mathrm{G}^{\prime \prime}$ of PLAP decreased gradually, then, both of them decreased sharply when the temperature was higher. There was a cross-over point for $\mathrm{G}^{\prime}$ and $\mathrm{G}^{\prime \prime}$ at the temperature of $55^{\circ} \mathrm{C}$. The gel melting process was completed. There was thermal hysteresis demonstrated in the cooling curve of PLAP. It seemed that the gel structure was weak, unlike the gel fraction from psyllium reported by Guo et al. [13].

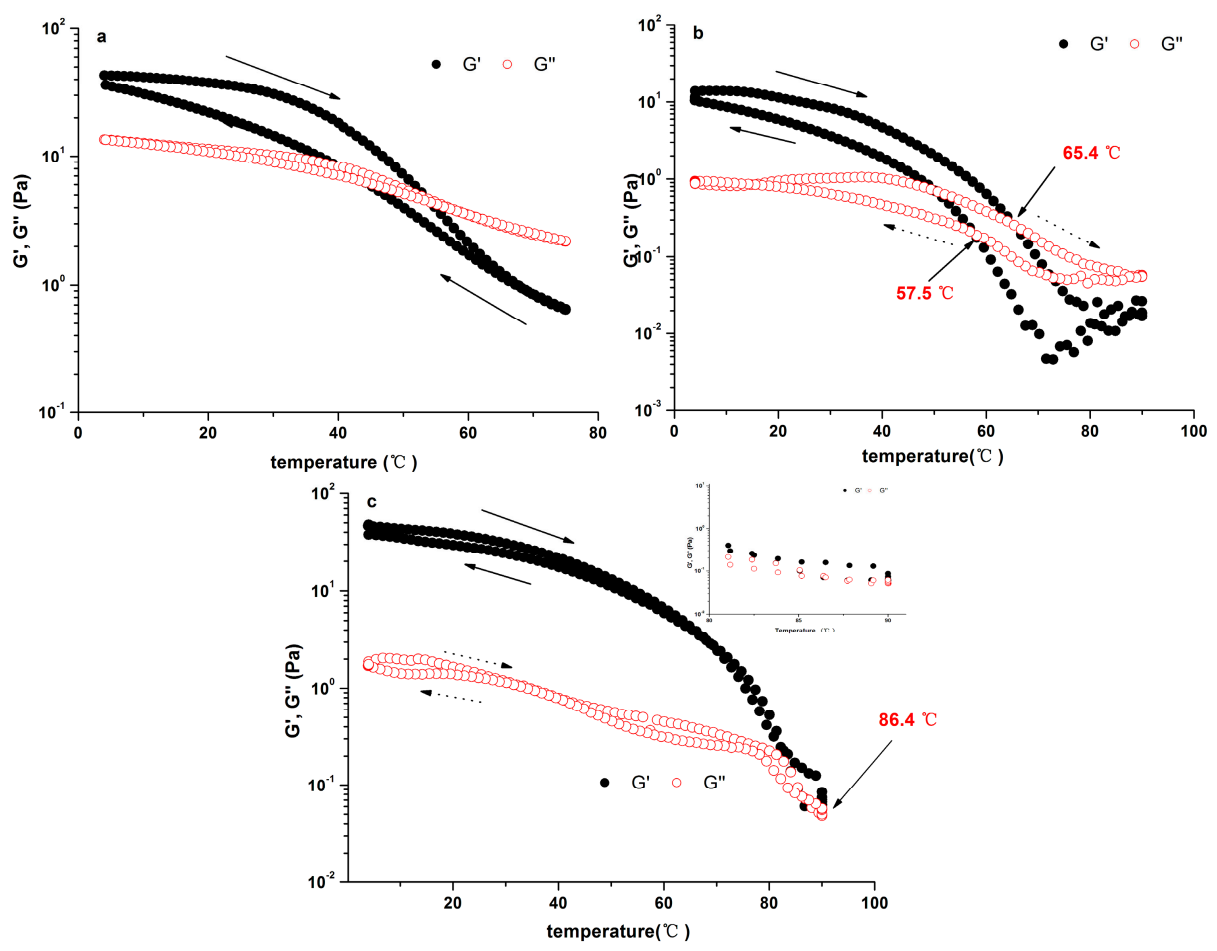

Figure 4. Variation in $\mathrm{G}^{\prime}$ and $\mathrm{G}^{\prime \prime}$ of polysaccharide during heating and cooling by $2{ }^{\circ} \mathrm{C} / \mathrm{min}$. (a) without salt-3.0\% PLAP; (b) with $0.2 \mathrm{M} \mathrm{Na}^{+}-1.0 \%$ PLCP; (c) with $0.2 \mathrm{M} \mathrm{Ca}^{2+}-1.0 \%$ PLCP. 


\subsection{Effects of $\mathrm{Na}^{+}$and $\mathrm{Ca}^{2+}$ on Rheological Properties of PLAP}

The gelling properties of PLAP were studied when the polysaccharide solution was added with $0.2 \mathrm{M} \mathrm{Na}^{+}$or $\mathrm{Ca}^{2+}$. The effects of $\mathrm{Ca}^{2+}$ and $\mathrm{Na}^{+}$on the frequency dependence of $\mathrm{G}^{\prime}$ and $\mathrm{G}^{\prime \prime}$ of PLAP are shown in Figure 5. It appeared that the strain dependence when the strain increased over $100 \%$. Therefore, a strain of 5\% was applied in the tests to make sure it was within the linear viscoelastic region. $G^{\prime}$ was higher than $G^{\prime \prime}$, and showed a weak dependence on frequency throughout all the frequency range. The spectrum of $\mathrm{G}^{\prime}$ and $\mathrm{G}^{\prime \prime}$ of PLAP with $0.2 \mathrm{M} \mathrm{Ca}^{2+}$ showed relatively less frequency dependence, suggesting PLAP with $0.2 \mathrm{M} \mathrm{Ca}^{2+}$ was more typical of a true gel.
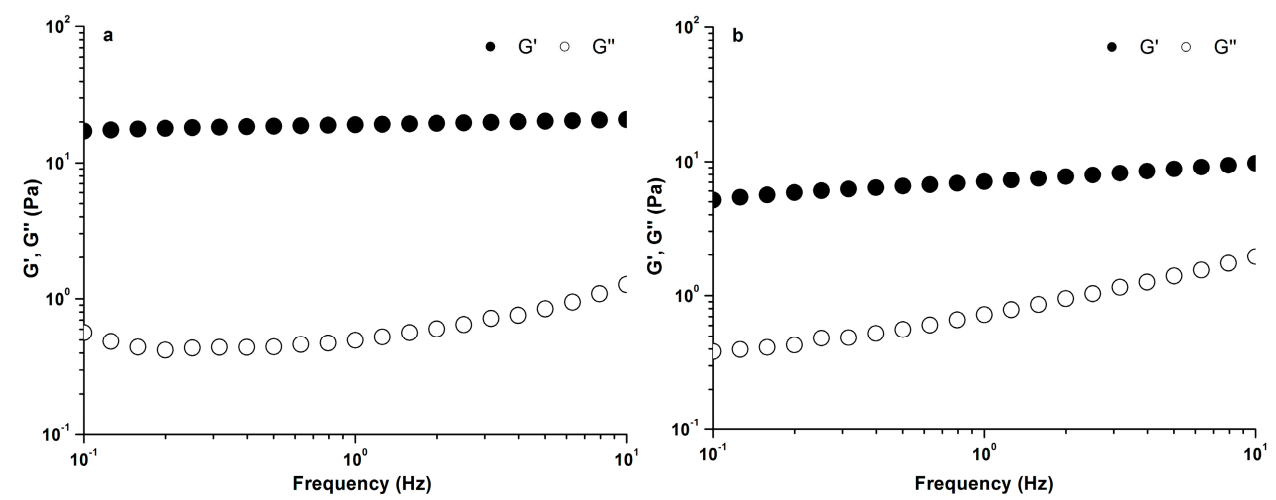

Figure 5. Mechanical spectra showing variation of $G^{\prime}$ and $G^{\prime \prime}$ with frequency of $1.0 \%$ PLAP with $0.2 \mathrm{M} \mathrm{Ca}^{2+}(\mathbf{a})$ or $0.2 \mathrm{M} \mathrm{Na}^{+}(\mathbf{b})$.

In order to deeply understand the influence of $\mathrm{Na}^{+}$and $\mathrm{Ca}^{2+}$ concentration on gelling properties of PLAP, elastic modulus $\mathrm{G}^{\prime}$ and critical strain (S) of the polysaccharide were compared by adding different concentrations of $\mathrm{Na}^{+}$or $\mathrm{Ca}^{2+}$, using strain sweep tests. The critical strain $\mathrm{S}$ was defined as the strain where $\mathrm{G}^{\prime}$ decreased sharply in the test, reflecting the deformability of a gel, and $\mathrm{G}^{\prime}$ was obtained in the linear region of the gel. The results are shown in Figures 6 and 7, respectively. It was found that $\mathrm{G}^{\prime}$ values increased greatly with increasing of $\mathrm{Ca}^{2+}$ concentration, especially when it was lower than $0.04 \mathrm{M}$. Then, the $\mathrm{G}^{\prime}$ value decreased when $\mathrm{Ca}^{2+}$ concentration was $0.05 \mathrm{M}$. The gel strength $\left(\mathrm{G}^{\prime}\right)$ increased again with increasing concentration of $\mathrm{Ca}^{2+}$, but the rate was a little slower. As for the critical strain $\mathrm{S}$, it obviously decreased with increasing $\mathrm{Ca}^{2+}$ concentration. When the concentration of $\mathrm{Ca}^{2+}$ was higher than $0.05 \mathrm{M}$, critical strain $\mathrm{S}$ was almost stable.
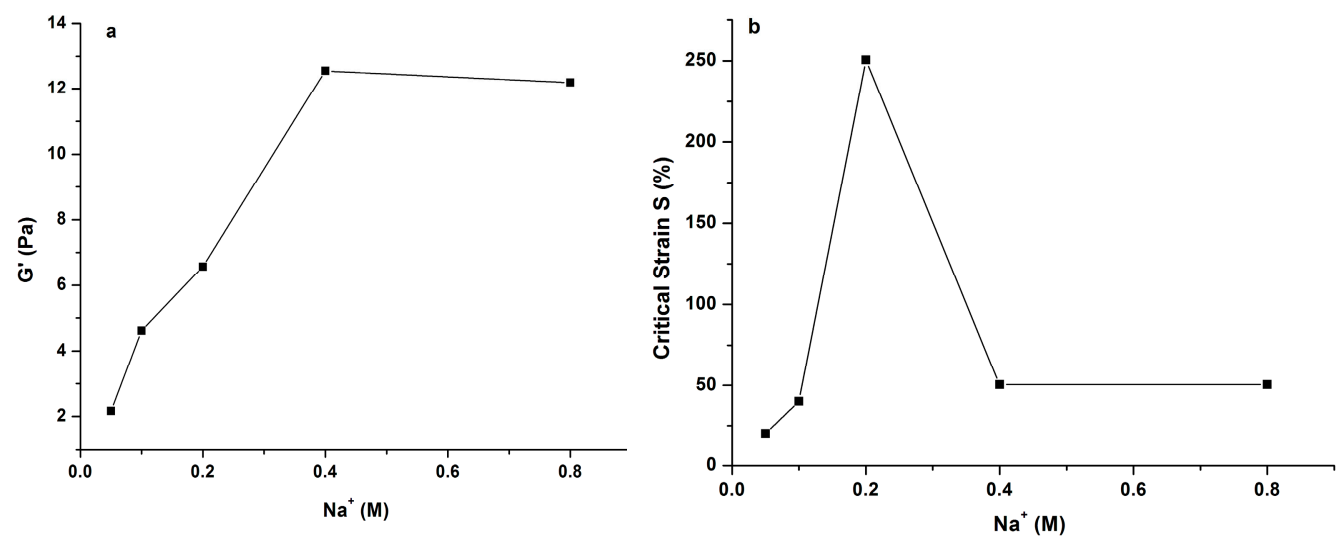

Figure 6. Variation of elastic modulus $\left(\mathrm{G}^{\prime}\right)(\mathbf{a})$ and critical strain $(\mathrm{S})(\mathbf{b})$ of $1.0 \%$ PLAP added with $0.2 \mathrm{M} \mathrm{Na}^{+}$. 

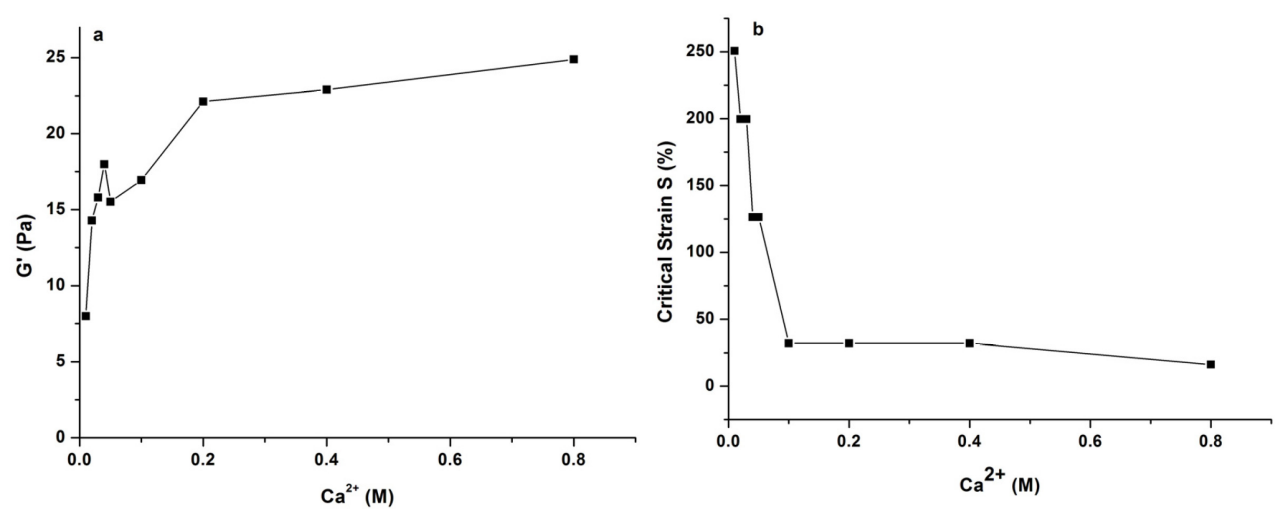

Figure 7. Variation of elastic modulus $\left(\mathrm{G}^{\prime}\right)(\mathbf{a})$ and critical strain (S) (b) of 1.0\% PLAP added with $0.2 \mathrm{M} \mathrm{Ca}^{2+}$.

When it came to $\mathrm{Na}^{+}$, it was obviously different. The gel strength was much weaker than that of PLAP with $\mathrm{Ca}^{2+}$ at the same ion concentration. It increased slowly, and did not increase any more when the concentration of $\mathrm{Na}^{+}$was higher than $0.4 \mathrm{M}$. For critical strain $\mathrm{S}$, it reached the highest value when the concentration of $\mathrm{Na}^{+}$was $0.2 \mathrm{M}$. Then, it decreased with increasing of $\mathrm{Na}^{+}$concentration.

On the basis of the above results, it is indicated that the mixture of PLAP solution with $0.2 \mathrm{M} \mathrm{Ca}^{2+}$ was more typical of a true gel. Figure $4 b, c$ show the changes of $G^{\prime}$ and $G^{\prime \prime}$ with temperature for $1 \%$ PLAP addition with $\mathrm{Na}^{+}$or $\mathrm{Ca}^{2+}$. At low temperature, both $\mathrm{G}^{\prime}$ and $\mathrm{G}^{\prime \prime}$ of the polysaccharide solution changed gradually. When the temperature increased, $\mathrm{G}^{\prime}$ and $\mathrm{G}^{\prime \prime}$ values of PLAP addition with $0.2 \mathrm{M} \mathrm{Na}^{+}$decreased more obviously than that of PLAP containing $0.2 \mathrm{M} \mathrm{Ca}^{+}$. The heating and cooling curves of $1.0 \%$ PLAP added with $0.2 \mathrm{M} \mathrm{Ca}^{2+}$ were superimposed, different from the original solution or the polysaccharide solution added with $0.2 \mathrm{M} \mathrm{Na}^{+}$, where both of them exhibited pronounced thermal hysteresis phenomenon. A sharp decrease in $\mathrm{G}^{\prime}$ and $\mathrm{G}^{\prime \prime}$ above $\sim 50{ }^{\circ} \mathrm{C}$ for $1.0 \%$ PLAP addition with $0.2 \mathrm{M} \mathrm{Na}^{+}$and $\sim 70{ }^{\circ} \mathrm{C}$ for $1.0 \%$ PLAP addition with $0.2 \mathrm{M} \mathrm{Ca}^{2+}$ was observed. This phenomenon suggested characteristic gel melting. The melting process changed gradually, and the cross point was detected at $65.4^{\circ} \mathrm{C}$ for the sample addition with $0.2 \mathrm{M} \mathrm{Na}^{+}$. It was $86.4{ }^{\circ} \mathrm{C}$ for $1.0 \%$ PLAP addition with $0.2 \mathrm{M} \mathrm{Na}^{+}$. These results suggested that the gel of $1.0 \%$ PLAP addition with $\mathrm{Ca}^{2+}$ was more stable during the temperature increasing.

\section{Discussion}

Polysaccharide extracted from Plantago seeds is usually arabinoxylan, although it was reported to contain small amount of uronic acid $[7,8,15,16,26-28]$. In this study, the alkaline extracted polysaccharide from the seeds of $P$. asiatica L. was confirmed to be highly branched arabinoxyaln and contain uronic acid, which was in accordance with polysaccharide from other psyllium resources. Intrinsic viscosity is a measure of the hydrodynamic volume occupied by the polysaccharide chains in a certain solvent. Few studies have reported intrinsic viscosity information of psyllium polysaccharide, except some data on arabinoxylan from maize, rye and wheat. The intrinsic viscosity of PLAP was $5.81 \mathrm{dL} / \mathrm{mg}$ in $0.1 \mathrm{M} \mathrm{NaCl}$, which was close to that of the water-extracted fraction from the same sources [29]. It was also similar to values of some arabinoxylan reported by Rattan et al. [30] and Cui and Mazza [31], but slightly higher than other reported intrinsic viscosities that ranged from 2 to $4 \mathrm{dL} / \mathrm{g}[22,32]$. The botanical differences, sample preparation, together with the uronic acid contents may combine to account for the different intrinsic viscosity.

A shear thinning liquid is a kind of non-Newtonian fluid as its apparent viscosity decreases with increasing shear rate. PLAP solutions at higher concentration showed more significant shear thinning behavior. The shear thinning appeared at lower shear rate, and the viscosity reduction is more pronounced for $3.0 \%$ PLAP than those with lower concentration. The shear thinning behavior was also 
widely reported for polysaccharides from other psylliums [12-14,17]. Although a strong hydrogen bonding exists among chains of $\beta$-1,4-linked xylose [31], the presence of arabinose side residues would reduce interaction among arabinoxylan chains which lead to less aggregation and lower viscosity of polysaccharide solution. This could explain why the highly branched PLAP only showed weak gel properties. However, both the apparent viscosity and gel strength of PLAP were much higher than that of arabinoxylan from cereals $[21,22,30]$. The high molecular weight of the polysaccharide may be one of the important reasons for this.

The shear viscosity and gel structure of polysaccharide solutions containing carboxylic acid groups are sensitive to ionic strength. Both water-extracted polysaccharide [17] and the alkaline-extracted fraction from the seeds of $P$. asiatica L. showed weak gel properties. An addition of $\mathrm{Na}^{+} \mathrm{or} \mathrm{Ca}^{2+}$ could significantly increase their gel strength. Some differences of rheological features, such as the divergence in apparent viscosity and gel strength, may be attributed to structural differences between the two fractions. Alkaline treatment may be another reason because de-esterification reactions probably occurred, which could break di- and triferulate crosslinks between polymer chains, and single ferulic acid residues [32]. As we know, gelation of some polymers is thermoreversible as gels could be formed during the cooling process of hot solutions and reversibly melted during heating process. The setting and melting temperature could be characterized as thermoreversible. When the melting temperature is higher than the setting temperature, the gel is considered to exhibit thermal hysteresis [33]. There was thermal hysteresis for 3.0\% PLAP. Although both the melting and setting temperature of $1.0 \%$ PLAP with an addition of $0.2 \mathrm{M} \mathrm{Na}^{+}$was higher than that of 3.0\% PLAP, there was still thermal hysteresis. As for the gel of $1.0 \%$ PLAP added with $0.2 \mathrm{M} \mathrm{Ca}^{2+}$, the melting temperature was almost equal to its setting temperature. This means $\mathrm{Ca}^{2+}$ plays a more significant role than $\mathrm{Na}^{+}$does in altering the thermal properties of PLAP gel.

\section{Materials and Methods}

\subsection{Materials}

The seeds of P. asiatica L. were purchased from Ji'an County (Ji'an, Jiangxi Province, China) and dried before use. Monosaccharide standards of mannose (Man), rhamnose (Rha), ribose (Rib), galactose (Gal), xylose (Xyl), arabinose (Ara), fucose (Fuc) and glucose (Glc) were obtained from Sigma Chemical Co. (St. Louis, MO, USA). Aqueous solutions were prepared with ultra-pure water from a Milli-Q water purification system (Millipore, Bedford, MA, USA). All other reagents were of analytical grade.

\subsection{Polysaccharide Preparation}

Seeds of Plantago asiatica L. were first extracted with boiling water twice to remove the water-extracted polysaccharide. Then, the residue was extracted twice with $0.5 \mathrm{M} \mathrm{NaOH}$ for $2 \mathrm{~h}$ at $4{ }^{\circ} \mathrm{C}$. The combined extract was filtered, neutralized with acetic acid, and concentrated on a rotary evaporator at $55^{\circ} \mathrm{C}$. The concentrated solution was added ethanol at a final concentration of $80 \%$. Then, the polysaccharide was redissolved in water, and deproteinated according to the Sevag method [34]. The resulting aqueous solution was dialyzed, and precipitated again with ethanol $(80 \%, v / v)$. After centrifugation, the precipitate was successively washed with anhydrous ethanol, acetone and diethyl ether. Final obtained polysaccharide PLAP was subjected to vacuum drying.

\subsection{Physicochemical Characteristics}

PLAP were analyzed for sugar contents [35,36], uronic acid contents [37] and protein contents [38]. Intrinsic viscosity determination was performed at $25.0^{\circ} \mathrm{C}$ in $0.1 \mathrm{M} \mathrm{NaCl}$ solvent, using an Ubbelohde Capillary Viscometer (Cannon Institution Company, State College, PA, USA). The polysaccharide was hydrolyzed by $2 \mathrm{M}$ TFA at $100^{\circ} \mathrm{C}$ for $12 \mathrm{~h}$ and used for monosaccharide composition analysis using a GC method [39]. 
The molecular weight of PLAP was determined by size exclusion chromatography using multiple detectors [29]: an 18-angle laser light scattering detector (GaAs3 semiconductor laser, $\lambda=658 \mathrm{~nm}$, eighteen angles, Dawn Heleos II, Wyatt Technology Corporation, Santa Barbara, CA, USA), a differential pressure viscometer (DP) (Visco Star II, Wyatt Technology Corporation), and a refractive index detector (RI) (OPTILAB T-rEX, Wyatt Technology Corporation). The OHpak SB-G guard column $(50 \mathrm{~mm} \times 6.0 \mathrm{~mm}$ I.D., $10 \mu \mathrm{m})$, OHpak SB-804 HQ column $(300 \mathrm{~mm} \times 8.0 \mathrm{~mm}$ I.D., $10 \mu \mathrm{m})$, and OHpak SB-806 HQ column $(300 \mathrm{~mm} \times 8.0 \mathrm{~mm}$ I.D., $13 \mu \mathrm{m})$, all of which were from Shodex Denko Inc. (New York, NY, USA) were used in series. The mobile phase was composed of $0.1 \mathrm{M} \mathrm{NaNO}_{3}$ and $0.02 \%(w / w) \mathrm{NaN}_{3}$ at the flow rate of $0.60 \mathrm{~mL} / \mathrm{min}$. PLAP was dissolved by the mobile phase at a concentration of $0.5 \mathrm{mg} / \mathrm{mL}$. A refractive index increment $(\mathrm{dn} / \mathrm{dc})$ of 0.146 was used for the calculation.

\subsection{Methylation Analysis}

Methylation analysis of PLAP was conducted according to the method of previous reports $[40,41]$ with some modifications. The partially methylated alditol acetates (PMAA) of PLAP were taken for linkage analysis using a 7890-7000A GC-MS system (Agilent, Santa Clara, CA, USA) equipped with a SP-2330 column (Supelco, Bellefonte, PA, USA; $30 \mathrm{~m} \times 0.25 \mathrm{~mm}, 0.2 \mu \mathrm{m}$ film thickness). Individual peaks of the PMAA and fragmentation patterns were identified by their mass spectra and relative retention times in the GC traces.

\subsection{Rheological Measurements}

PLAP was prepared by dissolving in ultra-pure water $(1.0 \%, w / v)$ and heating at $55{ }^{\circ} \mathrm{C}$ with constant stirring, then cooled down to room temperature before steady and dynamic rheological analysis. These were also carried out with PLAP at concentrations of $0.1,0.25,0.5,2.0$ and $3.0 \%(w / v)$ in ultra-pure water, and at $1.0 \%$ in $0.001,0.01,0.1,1.0 \mathrm{M} \mathrm{NaCl}$ or $\mathrm{CaCl}_{2}$ solutions. Rheological properties of the gels were measured under low-amplitude oscillatory shear using cone-and-plate $(50 \mathrm{~mm}$ diameter with a gap of $0.046 \mathrm{~mm}$, for the measurements of polysaccharide solutions in lower viscosity) or parallel plate $(50 \mathrm{~mm}$ diameter with a gap of $0.50 \mathrm{~mm}$, the measurements of polysaccharide solutions in higher viscosity or gel) geometry on an ARES Rheometer (TA Instruments, New Castle, DE, USA). All sample measurements were performed in linear viscoelastic region. The oscillatory rheological parameters used to compare the viscoelastic were: storage modulus $\left(G^{\prime}\right)$ and loss modulus $\left(G^{\prime \prime}\right)$. Samples were loaded onto the plate at $5{ }^{\circ} \mathrm{C}$ then heated to high temperature for temperature ramp test, and temperature was controlled by a SR5 Peltier Circulator at $2{ }^{\circ} \mathrm{C} / \mathrm{min}$. The parallel plate (50 $\mathrm{mm}$ diameter) was set with a gap of $1.0 \mathrm{~mm}$ for the measurements.

\section{Conclusions}

PLAP is an acidic arabinoxylan, composed of 1,2,4-linked Xylp and 1,3,4-linked Xylp residues. PLAP showed pseudoplastic behavior and weak gelling properties. Sodium and especially calcium ions played a significant role in increasing the apparent viscosity and gel strength.

Acknowledgments: The financial support for this study by National High-tech R\&D Program of China (863 Program) (2013AA102102), National Natural Science Foundation of China (No.: 21564007, 31301434), Research Fund for the Doctoral Program of Higher Education of China (No.: 20133601120009) and State Key Laboratory of Food Science and Technology of Nanchang University (No.: SKLF-QN-201505) is gratefully acknowledged. The authors wish to thank Steve W. Cui, Qing Bin Guo and Cathy Wang from Agri-Food Canada for technical assistance, and Wei Zhou from the University of Queensland, Australia for kind discussions.

Author Contributions: S.P.N., M.Y.X. and J.Y.Y. conceived and designed the experiments; H.X.L. performed the physicochemical properties determination; J.Y.Y. and H.H.C. performed the rheological, structural characterization experiments and analyzed the data; S.P.N. and J.Y.Y. wrote the paper.

Conflicts of Interest: The authors declare no conflict of interest. 


\section{References}

1. Broekaert, W.F.; Courtin, C.M.; Verbeke, K. Prebiotic and other health-related effects of cereal-derived arabinoxylans, arabinoxylan-oligosaccharides, and xylooligosaccharides. Crit. Rev. Food Sci. 2011, 51, 178-194. [CrossRef] [PubMed]

2. Ingerslev, A.K.; Theil, P.K.; Hedemann, M.S.; Laerke, H.N.; Knudsen, K.E. Resistant starch and arabinoxylan augment SCFA absorption, but affect postprandial glucose and insulin responses differently. Br. J. Nutr. 2014, 111, 1564-1576. [CrossRef] [PubMed]

3. Bernstein, A.M.; Titgemeier, B.; Kirkpatrick, K.; Golubic, M.; Roizen, M.F. Major cereal grain fibers and psyllium in relation to cardiovascular health. Nutrients 2003, 5, 1471-1487. [CrossRef] [PubMed]

4. Savitha Prashanth, M.R.; Shruthi, R.R.; Muralikrishna, G. Immunomodulatory activity of purified arabinoxylans from finger millet (Eleusine coracana, v. Indaf 15) bran. J. Food Sci. Technol. 2015, 52, 6049-6054. [CrossRef] [PubMed]

5. Pérez-Martínez, A.; Valentín, J.; Fernández, L.; Hernández-Jiménez, E.; López-Collazo, E.; Zerbes, P.; Schwörer, E.; Nuñéz, F.; Martín, I.G.; Sallis, H.; et al. Arabinoxylan rice bran (MGN-3/Biobran) enhances natural killer cell-mediated cytotoxicity against neuroblastoma in vitro and in vivo. Cytotherapy 2015, 17, 601-612. [CrossRef] [PubMed]

6. Al-Assaf, S.; Phillips, G.O.; Williams, P.A.; Takigami, S.; Dettmar, P.; Havler, M. Molecular weight, tertiary structure, water binding and colon behaviour of ispaghula husk fibre. Proc. Nutr. Soc. 2003, 62, 211-216. [CrossRef] [PubMed]

7. Guo, Q.; Cui, S.W.; Wang, Q.; Christopher Young, J. Fractionation and physicochemical characterization of psyllium gum. Carbohydr. Polym. 2008, 73, 35-43. [CrossRef]

8. Kennedy, J.F.; Sandhu, J.S.; Southgate, D.A. Structural data for the carbohydrate of ispaghula husk ex Plantago ovata forsk. Carbohydr. Res. 1979, 75, 265-274. [CrossRef]

9. Pawar, H.; Varkhade, C. Isolation, characterization and investigation of Plantago ovata husk polysaccharide as superdisintegrant. Int. J. Biol. Macromol. 2014, 69, 52-58. [CrossRef] [PubMed]

10. Zhao, H.; Wang, Q.; Sun, Y.; Yang, B.; Wang, Z.; Chai, G.; Guan, Y.; Zhu, W.; Shu, Z.; Lei, X.; et al. Purification, characterization and immunomodulatory effects of Plantago depressa polysaccharides. Carbohydr. Polym. 2014, 112, 63-72. [CrossRef] [PubMed]

11. Gonçalves, S.; Romano, A. The medicinal potential of plants from the genus Plantago (Plantaginaceae). Ind. Crop. Prod. 2016, 83, 213-226. [CrossRef]

12. Farahnaky, A.; Askari, H.; Majzoobi, M.; Mesbahi, G. The impact of concentration, temperature and $\mathrm{pH}$ on dynamic rheology of psyllium gels. J. Food Eng. 2010, 100, 294-301. [CrossRef]

13. Guo, Q.; Cui, S.W.; Wang, Q.; Goff, H.D.; Smith, A. Microstructure and rheological properties of psyllium polysaccharide gel. Food Hydrocoll. 2009, 23, 1542-1547. [CrossRef]

14. Haque, A.; Richardson, R.K.; Morris, E.R.; Dea, I. Anthan-like 'weak gel' rheology from dispersions of ispaghula seed husk. Carbohydr. Polym. 1993, 22, 223-232. [CrossRef]

15. Yin, J.Y.; Lin, H.; Li, J.; Wang, Y.; Cui, S.W.; Nie, S.P.; Xie, M.Y. Structural characterization of a highly branched polysaccharide from the seeds of Plantago asiatica L. Carbohydr. Polym. 2012, 87, 2416-2424. [CrossRef]

16. Yin, J.Y.; Lin, H.X.; Nie, S.P.; Cui, S.W.; Xie, M.Y. Methylation and 2D NMR analysis of arabinoxylan from the seeds of Plantago asiatica L. Carbohydr. Polym. 2012, 88, 1395-1401. [CrossRef]

17. Yin, J.Y.; Nie, S.P.; Li, J.; Li, C.; Cui, S.W.; Xie, M.Y. Mechanism of interactions between calcium and viscous polysaccharide from the seeds of Plantago asiatica L. J. Agric. Food Chem. 2012, 60, 7981-7987. [CrossRef] [PubMed]

18. Hu, J.L.; Nie, S.P.; Min, F.F.; Xie, M.Y. Polysaccharide from seeds of Plantago asiatica L. increases short-chain fatty acid production and fecal moisture along with lowering $\mathrm{pH}$ in mouse colon. J. Agric. Food Chem. 2012, 60, 11525-11532. [CrossRef] [PubMed]

19. Hu, J.L.; Nie, S.P.; Li, C.; Fu, Z.H.; Xie, M.Y. Microbial short-chain fatty acid production and extracellular enzymes activities during in vitro fermentation of polysaccharides from the seeds of Plantago asiatica $\mathrm{L}$. treated with microwave irradiation. J. Agric. Food Chem. 2013, 61, 6092-6101. [CrossRef] [PubMed]

20. Hu, J.L.; Nie, S.P.; Wu, Q.M.; Li, C.; Fu, Z.H.; Gong, J.; Cui, S.W.; Xie, M.Y. Polysaccharide from seeds of Plantago asiatica L. affects lipid metabolism and colon microbiota of mouse. J. Agric. Food Chem. 2014, 62, 229-234. [CrossRef] [PubMed] 
21. Kale, M.S.; Pai, D.A.; Hamaker, B.R.; Campanella, O.H. Structure-function relationships for corn bran arabinoxylans. J. Cereal Sci. 2010, 52, 368-372. [CrossRef]

22. Skendi, A.; Biliaderis, C.; Izydorczyk, M.; Zervou, M.; Zoumpoulakis, P. Structural variation and rheological properties of water-extractable arabinoxylans from six Greek wheat cultivars. Food Chem. 2011, 126, 526-536. [CrossRef]

23. Clark, A.H.; Ross-Murphy, S.B. Structural and mechanical properties of biopolymer gels. Biopolymers 1987, 83, 57-192.

24. Rincón, F.; Muñoz, J.; León de Pinto, G.; Alfaro, M.; Calero, N. Rheological properties of Cedrela odorata gum exudate aqueous dispersions. Food Hydrocoll. 2009, 23, 1031-1037. [CrossRef]

25. Simas-Tosin, F.; Barraza, R.; Petkowicz, C.; ilveira, J.; Sassaki, G.; Santos, E.; Gorin, P.; Iacomini, M. Rheological and structural characteristics of peach tree gum exudate. Food Hydrocoll. 2010, 24, 486-493. [CrossRef]

26. Fischer, M.H.; Yu, N.; Gray, G.R.; Ralph, J.; Anderson, L.; Marlett, J.A. The gel-forming polysaccharide of psyllium husk (Plantago ovata Forsk). Carbohydr. Res. 2004, 339, 2009-2017. [CrossRef] [PubMed]

27. Gong, L.; Zhang, H.; Niu, Y.; Chen, L.; Liu, J.; Alaxi, S.; Shang, P.; Yu, W.; Yu, L. A novel alkali extractable polysaccharide from Plantago asiatic L. seeds and its radical-scavenging and bile acid-binding activities. J. Agric. Food Chem. 2015, 63, 569-577. [CrossRef] [PubMed]

28. Samuelsen, A.; Lund, I.; Djahromi, J.; Paulsen, B.; Wold, J.; Knutsen, S. Structural features and anti-complementary activity of some heteroxylan polysaccharide fractions from the seeds of Plantago major $\mathrm{L}$. Carbohydr. Polym. 1999, 38, 133-143. [CrossRef]

29. Yin, J.Y.; Nie, S.P.; Guo, Q.B.; Wang, Q.; Cui, S.W.; Xie, M.Y. Effect of calcium on solution and conformational characteristics of polysaccharide from seeds of Plantago asiatica L. Carbohydr. Polym. 2015, 124, 331-336. [CrossRef] [PubMed]

30. Rattan, O.; Izydorczyk, M.S.; Biliaderis, C.G. Structure and rheological behaviour of arabinoxylans from Canadian bread wheat flours. LWT-Food Sci. Technol. 1994, 27, 550-555. [CrossRef]

31. Cui, W.; Mazza, G. Physicochemical characteristics of flaxseed gum. Food Res. Int. 1996, 29, $397-402$. [CrossRef]

32. Qian, K.; Cui, S.; Wu, Y.; Goff, H. Flaxseed gum from flaxseed hulls: Extraction, fractionation, and characterization. Food Hydrocoll. 2012, 28, 275-283. [CrossRef]

33. Wang, Q.; Cui, S.W. Understanding the physical properties of food polysaccharides. In Food Carbohydrates: Chemistry, Physical Properties, and Applications; Cui, S.W., Ed.; CRC Press: Boca Raton, FL, USA, 2005.

34. Staub, A. Removal of protein-Sevag method. Methods Carbohydr. Chem. 1965, 5, 5-6.

35. Dubois, M.; Gilles, K.A.; Hamilton, J.K.; Rebers, P.T.; Smith, F. Colorimetric method for determination of sugars and related substances. Anal. Chem. 1956, 28, 350-356. [CrossRef]

36. Zhou, C.; Xie, M.Y.; Wan, Y.; Nie, S.P. Study on determination of the contents of polysaccharides in Semen Plantaginis. Chin. J. Anal. Lab. 2008, 27, 10.

37. Blumenkrantz, N.; Asboe-Hansen, G. New method for quantitative determination of uronic acids. Anal. Biochem. 1973, 54, 484-489. [CrossRef]

38. Bradford, M.M. A rapid and sensitive method for the quantitation of microgram quantities of protein utilizing the principle of protein-dye binding. Anal. Biochem. 1976, 72, 248-254. [CrossRef]

39. Chen, Y.; Xie, M.Y.; Nie, S.P.; Li, C.; Wang, Y.X. Purification, composition analysis and antioxidant activity of a polysaccharide from the fruiting bodies of Ganoderma atrum. Food Chem. 2008, 107, 231-241. [CrossRef]

40. Ciucanu, I.; Kerek, F.A. Simple and rapid method for the permethylation of carbohydrates. Carbohydr. Res. 1984, 131, 209-217. [CrossRef]

41. Yin, J.Y.; Chan, B.C.L.; Yu, H.; Lau, I.Y.K.; Han, X.Q.; Cheng, S.W.; Wong, C.K.; Lau, C.B.S.; Xie, M.Y.; Fung, K.P. Separation, structure characterization, conformation and immunomodulating effect of a hyperbranched heteroglycan from Radix Astragali. Carbohydr. Polym. 2012, 87, 667-675. [CrossRef]

Sample Availability: Samples of the compounds PLAP are available from the authors.

(C) 2016 by the authors; licensee MDPI, Basel, Switzerland. This article is an open access article distributed under the terms and conditions of the Creative Commons Attribution (CC-BY) license (http:/ / creativecommons.org/licenses/by/4.0/). 